\title{
Fullerenelike arrangements in carbon nitride thin films grown by direct ion beam sputtering
}

\author{
R. Gago, ${ }^{a)}$ G. Abrasonis, A. Mücklich, and W. Möller \\ Institute of Ion Beam Physics and Materials Research, Forschungszentrum Rossendorf, PF-510119, \\ 01314 Dresden, Germany \\ Zs. Czigány and G. Radnóczi \\ Research Institute for Technical Physics and Materials Science, Hungarian Academy of Sciences, \\ P.O. Box 49, H-1525 Budapest, Hungary
}

(Received 20 April 2005; accepted 16 June 2005; published online 8 August 2005)

\begin{abstract}
Carbon nitride $\left(\mathrm{CN}_{x}\right)$ thin films were grown by direct $\mathrm{N}_{2} / \mathrm{Ar}$ ion beam sputtering of a graphite target at moderate substrate temperatures $(300-750 \mathrm{~K})$. The resulting microstructure of the films was studied by high-resolution transmission electron microscopy. The images showed the presence of curved basal planes in fullerenelike arrangements. The achievement and evolution of these microstructural features are discussed in terms of nitrogen incorporation, film-forming flux, and ion bombardment effects, thus adding to the understanding of the formation mechanisms of curved graphitic structures in $\mathrm{CN}_{x}$ materials. (C) 2005 American Institute of Physics.
\end{abstract}

[DOI: $10.1063 / 1.2008366$ ]

The theoretical work of Cohen and $\mathrm{Liu}^{1}$ predicting the hypothetical $\beta-\mathrm{C}_{3} \mathrm{~N}_{4}$ phase harder than diamond has motivated an intense research in carbon nitride $\left(\mathrm{CN}_{x}\right)$ materials during the last years. However, most of the attempts to synthesize this phase have resulted in amorphous graphitic structures and a limitation in the maximum nitrogen content incorporated to the films below 50 at. \%. ${ }^{2}$ Among these graphitic structures, an important finding is the evolution of fullerenelike (FL) features under certain growth conditions, consisting of bent and cross-linked nitrogen-containing graphite basal planes of nanoscale dimensions. ${ }^{3}$ This atomic arrangement improves significantly the mechanical performance of the material, being compliant and tough at the same time, and making it a promising candidate for tribological applications. ${ }^{4}$ The orientation, corrugation, folding, and cross-linking of the basal planes determines the actual physical properties of the graphitic solid, which exhibits a 3D superstructure that exploits the in-plane strength of $s p^{2}$ hybrids. These arrangements are not restricted to $\mathrm{CN}_{x}$ solids and have been found in other laminar materials. ${ }^{5}$ As compared with pure $\mathrm{C}$ materials, the introduction of $\mathrm{N}$ reduces the energy barrier to induce curvature in the basal planes. ${ }^{6,7}$

So far, the production of well-structured FL-CN $\mathrm{C}_{x}$ thin films has been only reported by reactive dc magnetron sputtering (dc-MS) while, recently, pulsed laser deposition (PLD) resulted also in partially structured films. ${ }^{8}$ Low-energy $(<100 \mathrm{eV})$ ion bombardment and moderate substrate temperatures $(400-800 \mathrm{~K})$ have been shown to be essential for the synthesis of FL-CN $\mathrm{C}_{x}$ thin films by dc-MS. ${ }^{9}$ The required growth conditions are necessary to promote threefold $\mathrm{N}$ bonding environments over $\mathrm{N}$ atoms in low-coordination sites (i.e., pyridine- and cyanogenlike environments). ${ }^{10}$ This indicates that threefold $\mathrm{N}$ atoms, either in graphitelike or pyrrolelike environments, are the driving force for the inser-

\footnotetext{
a) Author to whom correspondence should be addressed; electronic mail: raul.gago@uam.es. Present address: Centro de Micro-Análisis de Materiales, Universidad Autónoma de Madrid, C/Faraday 3 (Edificio 22), Campus de Cantoblanco, 28049 Madrid, Spain.
}

tion of curvature in graphitic basal planes. Moreover, a large fraction of this arrangement is necessary for the evolution of well-structured FL- $\mathrm{CN}_{x}$. Therefore, FL-CN ${ }_{x}$ formation should be promoted by the suppression of the less-favorable bonding configurations as, in this case, low coordination sites.

Despite the successful synthesis of FL-CN ${ }_{x}$, the growth mechanisms are still not fully understood. This is partially due to the limitation in the growth techniques yielding FL- $\mathrm{CN}_{x}$. From previous results, it has been concluded that, in addition to the role of $\mathrm{N}$ atoms, $\mathrm{C}_{x} \mathrm{~N}_{y}(x, y \leqslant 2)$ species emitted from the sputtering target might contribute as filmforming species and imprint their structure on the evolving microstructure. ${ }^{11}$ The relevance of $\mathrm{C}_{x} \mathrm{~N}_{y}$ precursors from the target has been supported by the lack of FL arrangements in $\mathrm{CN}_{x}$ films prepared by e-beam evaporation of graphite under low-energy $(\sim 60 \mathrm{eV})$ nitrogen ion beam assistance. ${ }^{12}$

Here, $\mathrm{CN}_{x}$ films are grown by direct $\mathrm{N}_{2} / \mathrm{Ar}$ ion beam sputtering (IBS) of a graphite target to mimic the dc-MS process and, in this way, introduce single- and multi-atomic $\mathrm{C}_{x} \mathrm{~N}_{y} \quad(0 \leqslant x, y \leqslant 2)$ species with hyperthermal energies $(\sim 1-10 \mathrm{eV})$ in the film-forming flux. $\mathrm{CN}_{x}$ films deposited in this way exhibit fullerenelike features with standing graphitic basal planes but they are less structured as compared to FL-CN ${ }_{x}$ grown by dc-MS. The achievement and extension of these microstructural features is discussed in terms of the resulting bonding configurations, film-forming species, and ion bombardment effects. The conclusions support the role of $\mathrm{C}_{x} \mathrm{~N}_{y}$ precursors for the microstructural evolution and the requirement of low-energy assistance to develop wellstructured FL-CN ${ }_{x}$.

Carbon (C) and $\mathrm{CN}_{x}$ thin films were grown by IBS of a 5 in. graphite target with $\mathrm{N}_{2} / \mathrm{Ar}$ sputtering gas mixtures at moderate substrate temperatures $(300,423,573$, and $723 \mathrm{~K})$ onto $\mathrm{Si}(100)$ and $\mathrm{NaCl}$ substrates. The ion beam was produced with a $3 \mathrm{~cm}$ Kaufman ion gun located $\sim 11 \mathrm{~cm}$ away from the target. The ions impinged at an angle of $40^{\circ}$ with respect to the target surface normal. The substrates were located facing the graphite target at a distance of $\sim 30 \mathrm{~cm}$. 


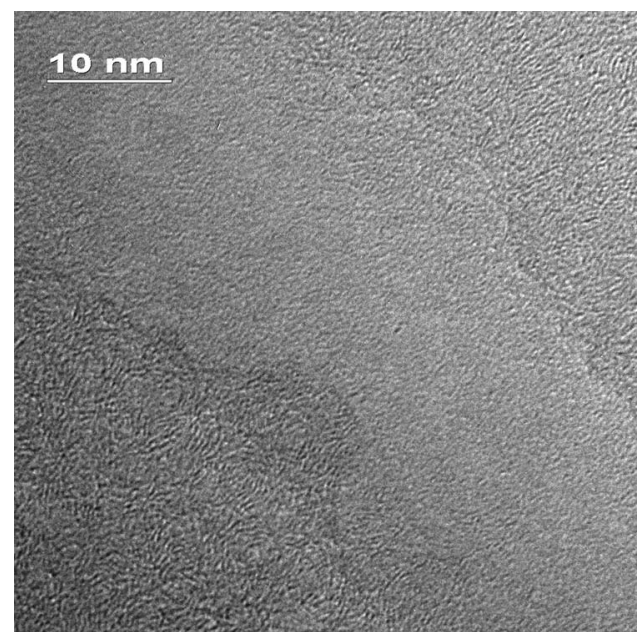

FIG. 1. Plan-view HRTEM image of a $\mathrm{CN}_{x}$ film grown by IBS at $573 \mathrm{~K}$ with a pure $\mathrm{N}_{2}$ sputtering beam.

Before deposition, the substrates were cleaned for $10 \mathrm{~min}$ with $1 \mathrm{keV} \mathrm{Ar}^{+}$produced by an additional $5 \mathrm{~cm}$ Kaufman source facing the substrate. Further details about the growth method, composition and bonding structure of the films can be found in Ref. 13.

The microstructure was studied by high resolution transmission electron microscopy (HRTEM). Plan-view specimens were obtained from samples grown on $\mathrm{NaCl}$ substrates by floating-off technique while cross-sectional specimens were made by gluing slices from samples grown on $\mathrm{Si}(100)$ followed by mechanical thinning, polishing and thinned to electron transparency by ion beam milling with $10 \mathrm{keV} \mathrm{Ar}^{+}$ impinging at $4^{\circ}$ with respect to the surface. In the final period of the milling process, the ion energy was decreased gradually to $250 \mathrm{eV}$ to minimize surface amorphization. ${ }^{14,15}$ The investigations were made in a JEOL 3010 microscope operated at $300 \mathrm{kV}$ and a resolution of $0.17 \mathrm{~nm}$.

Figure 1 shows the HRTEM plan-view image of a $\mathrm{CN}_{x}$ sample grown by IBS at $573 \mathrm{~K}$ with a pure $\mathrm{N}_{2}$ sputtering beam. Ordered domains of several $\mathrm{nm}$ in size consisting of straight and curved planes typical of FL arrangements can be seen. These features are better observed at the thinnest parts of the sample where high resolution imaging is possible and the influence of overlapping of projected features is mini- mized. Similar microstructure was observed in the films grown with other $\mathrm{N}_{2} / \mathrm{Ar}$ mixtures and at $423 \mathrm{~K}$ and $723 \mathrm{~K}$.

The presence of microstructure in the films produced by IBS can be further proven by cross-section HRTEM images. The images taken from $\mathrm{C}$ and $\mathrm{CN}_{x}$ films prepared at $723 \mathrm{~K}$ are shown in Figs. 2(a) and 2(b), respectively. The $\mathrm{CN}_{x}$ was produced with a $\mathrm{N}_{2}$ content of $50 \%$ in the $\mathrm{Ar} / \mathrm{N}_{2}$ gas mixture. The image corresponding to the $\mathrm{C}$ film [Fig. 2(a)] shows a highly textured microstructure consisting of predominantly standing basal planes. The introduction of $\mathrm{N}$ [Fig. 2(b)] reduces the texture but promotes curvature in the basal planes. The preferential orientation of the basal planes was also observed in FL-CN ${ }_{x}$ grown by dc-MS. ${ }^{16}$ The corrugation with $\mathrm{N}$ introduction is in agreement with the hypothesis that $\mathrm{N}$ is crucial for the evolution of heavily bent and frequently cross-linked basal planes at much lower energies as compared to pure $\mathrm{C}$ films.

The problem of projection artifacts for imaging the structural features can be partially overcome by considering selective area electron diffraction (SAED), since any overlapping does not affect the characteristic lattice spacing in the diffraction pattern. ${ }^{17}$ In addition, the brightness and width of the diffraction pattern can be used to extract information on the degree of ordering. The corresponding SAED patterns are shown as insets in Fig. 2. They show diffuse features indicating the disordered structure of the film and corresponding to spacings of $\sim 1.15,1.95$, and $3.5 \AA$ [see labels in the inset of Fig. 2(c)]. In the insets of panels (b) and (c) in Fig. 2, the dot diffraction pattern of the crystalline $\mathrm{Si}(100)$ substrate is also superimposed to indicate the relation of the texture of FL features to the substrate normal. The rings at $\sim 1.15$ and $\sim 1.95 \AA$ coincide with those observed for amorphous allotropes of $\mathrm{C}$ and $\mathrm{CN}_{x}$ films while the innermost ring at $3.5 \AA$ match with the inter-plane separation of hexagonal basal planes in graphite (0002). The SAED images of Fig. 2 show a broad feature at $3.5 \AA$ indicating the presence of defective graphitic basal planes. The appearance of a broad arc is due to the preferential orientation of the basal planes perpendicular to the surface normal. The SAED from planview images of well-structured FL-CN ${ }_{x}$ presents a similar diffuse pattern but with more distinguishable features and an additional ring at $1.75 \AA \AA^{17}$ The intensity of this ring correlates with that at $3.5 \AA$ and, therefore, it is attributed to the
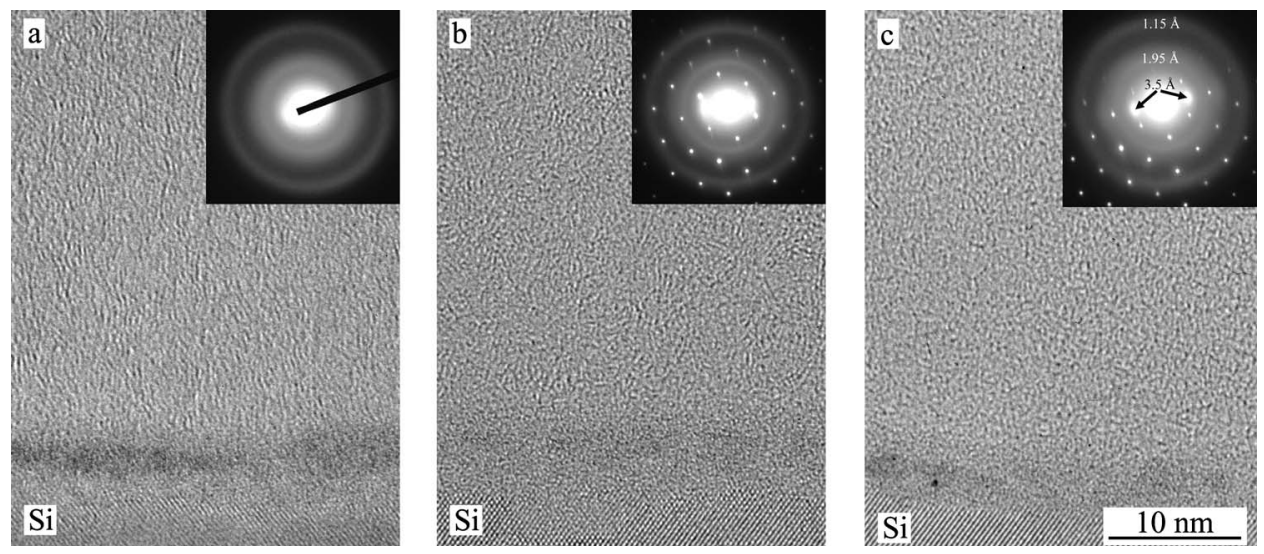

FIG. 2. Cross-section HRTEM images and SAED for (a) $\mathrm{C}$ and (b) $\mathrm{CN}_{x}\left(\mathrm{~N}_{2} / \mathrm{Ar}\right.$ ratio of 1 in the gas mixture) films grown by IBS at $723 \mathrm{~K}$. Panel (c) shows a $\mathrm{CN}_{x}$ film grown by IBS (with a pure $\mathrm{N}_{2}$ ion beam) at $723 \mathrm{~K}$ under concurrent $100 \mathrm{eV}$ nitrogen ion assistance. The SAED patterns in panels (b) and (c) show the dot diffraction pattern of the $\mathrm{Si}(100)$ substrate superimposed to the pattern of the film (diffuse features). 
interplane distance in graphite (0004). The presence and definition of the 3.5 and $1.75 \AA$ rings have been correlated with the evolution of the FL structure, as signatures of the short/medium range graphitic order. ${ }^{17}$ In the case of IBS films, the characteristic $3.5 \AA$ spacing shows similar structured films as those grown by dc-MS, but the diffuse ring at $1.75 \AA$ is less defined. This feature is only observable in the SAED pattern in Fig. 2(c) as an arc (almost incorporated into the diffuse ring at $1.95 \AA$ ) and aligned to the arc at $3.5 \AA$. These observations indicate a smaller degree of ordering or extension of the graphitic arrangements in IBS films as compared to their dc-MS counterparts. The latter conclusion can also be directly extracted from the comparison of the HRTEM images of Fig. 2 and those reported in Ref. 16.

The achievement of the FL microstructure in $\mathrm{CN}_{x}$ samples prepared by IBS indicates that, as expected, IBS mimics to some extent the growth by dc-MS. In this sense, significant amount of $\mathrm{N}$ (up to 20 at \%) can be incorporated in $\mathrm{CN}_{x}$ solid films by IBS of a graphite target, the main source of $\mathrm{N}$ coming from the nitridation of the target surface and the subsequent (chemical and physical) sputtering of atomic and molecular $\mathrm{N}$-containing species. The $\mathrm{N}$ incorporation by IBS is slightly below the values reported by dc-MS (up to 25 at \%) due to the suppression of the concurrent $\mathrm{N}$ ion bombardment on the substrate surface from the plasma discharge. However, not only the similar composition is critical for achieving structured films but also the way that $\mathrm{N}$ atoms are incorporated in the $\mathrm{C}$ atomic network. The comparison in Ref. 13 of the bonding structure of $\mathrm{CN}_{x}$ films grown by IBS and dc-MS also yielded in both cases a significant participation of three-fold nitrogen but a slightly higher relative content of cyanogenlike or nitrile bonding environments by IBS. The detrimental role of nitrile sites in FL arrangements is obvious since their terminating character hinders the further extension of graphene sheets, which could explain the lower degree of FL character in $\mathrm{FL}_{-} \mathrm{CN}_{x}$ films grown by IBS with respect to dc-MS.

The introduction of $\mathrm{N}_{2}$ ion assistance $(100 \mathrm{eV})$ during IBS was shown to induce a significant reduction of the relative content of nitrile bonding environments. ${ }^{13}$ Therefore, the less structured films grown by IBS can be partially attributed to the lack of ion assistance during growth. The influence of ion bombardment during growth is very complex, but the IBS process itself can be considered as the deposition of energetic particles with hyperthermal energies in the range of $1-10 \mathrm{eV} .{ }^{18}$ These energies are enough to introduce a significant amount of displacements on the surface of the growing film, as shown by the growth of dense $a$-C films. ${ }^{19}$ In this way, the formation of FL microstructure can be understood as a temperature and ion induced clustering process under impingement of hyper-thermal particles coming from the target (and from an assisting plasma or additional ion source) and site-selective incorporation of atomic and molecular $\mathrm{N}$-containing species. When the degree of assisting ion bombardment is moderate (low ion energy or/and flux) it activates the surface reaction pathways through which $\mathrm{N}$ atoms located at low coordination number sites are preferentially removed or transformed into bonding environments with higher coordination number. However, when the degree of ion bombardment increases above a certain threshold, it can lead to amorphization ${ }^{16}$ or complete resputtering ${ }^{9}$ of the growing film. These assumptions are corroborated by the HRTEM image shown in Fig. 2(c) obtained from a $\mathrm{CN}_{x}$ sample grown by IBS $\left(100 \% \mathrm{~N}_{2}\right.$ sputtering beam) and additional concurrent $100 \mathrm{eV}$ nitrogen ion beam assistance, the assisting ions impinging at normal incidence with respect to the substrate surface. The image indicates that although some microstructure remains, the relatively high-energy involved inhibits the evolution of extended FL domains. Lower energies could not be used due to experimental constraints but future experiments are in progress to reduce the energy of the assistance ions and, in this way, check the promotion of FL arrangements by ion assistance.

In conclusion, HRTEM images reveal the formation of FL-CN ${ }_{x}$ by IBS at moderate temperatures. This result supports the presence of $\mathrm{C}_{x} \mathrm{~N}_{y}$ species in the film-forming flux and low-energy ion bombardment as the main paths to induce the evolution of curved graphitic structures in $\mathrm{CN}_{x}$ solids. In addition, the formation of such structures is clearly related to the promotion of threefold $\mathrm{N}$ in hexagonal or pentagonal arrangements and a reduced participation of nitrile bonding environments.

This work has been carried out inside the IHP-Network "Synthesis, structure and properties of new fullerenelike materials" being supported by the EU Contract No. HPRN-CT2002-00209.

${ }^{1}$ A. Y. Liu and M. L. Cohen, Science 245, 841 (1989).

${ }^{2}$ C. Ronning, H. Feldermann, R. Merk, H. Hofsäss, P. Reinke, and J. U. Thiele, Phys. Rev. B 58, 2207 (1998).

${ }^{3}$ H. Sjöström, S. Stafström, M. Boman, and J. E. Sundgren, Phys. Rev. Lett. 75, 1336 (1995).

${ }^{4}$ L. Hultman, J. Neidhardt, N. Hellgren, H. Sjöström, and J.-E. Sundgren, Materials Research Society Bulletin 28, 19 (2003).

${ }^{5}$ I. Alexandrou, H. J. Scheibe, C. J. Kiely, A. J. Papworth, G. A. J. Amaratuga, and B. Schultrich, Phys. Rev. B 60, 10903 (1999).

${ }^{6}$ N. Lin, N. Hellgren, M. P. Johansson, L. Hultman, R. Erlandsson, and J.-E. Sundgren, Phys. Rev. B 61, 4898 (2000).

${ }^{7}$ S. Stafström, Appl. Phys. Lett. 77, 3941 (2000).

${ }^{8}$ A. A. Voevodin, J. G. Jones, J. S. Zabinski, Zs. Czigány, and L. Hultman, J. Appl. Phys. 92, 4980 (2002).

${ }^{9}$ N. Hellgren, K. Macák, E. Broitman, M. P. Johansson, L. Hultman, and J.-E. Sundgren, J. Appl. Phys. 88, 524 (2000).

${ }^{10}$ R. Gago, I. Jiménez, J. Neidhardt, B. Abendroth, I. Caretti, L. Hultman, and W. Möller, Phys. Rev. B 71, 125414 (2005).

${ }^{11}$ J. Neidhardt, B. Abendroth, R. Gago, W. Möller, and L. Hultman, J. Appl. Phys. 94, 7059 (2003).

${ }^{12}$ R. Gago, J. Neidhardt, M. Vinnichenko, U. Kreissig, A. Kolitsch, L. Hultman, and W. Möller, Thin Solid Films 483, 89 (2005).

${ }^{13}$ G. Abrasonis, R. Gago, I. Jiménez, U. Kreissig, A. Kolitsch, and W. Möller, J. Appl. Phys. (submitted).

${ }^{14}$ Á. Barna, B. Pécz, and M. Menyhárd, Ultramicroscopy 70, 161 (1998).

${ }^{15}$ Zs. Czigány, J. Neidhardt, I. F. Brunell, and L. Hultman, Ultramicroscopy 94, 163 (2002).

${ }^{16}$ J. Neidhardt, Zs. Czigány, I. F. Brunell, and L. Hultman, J. Appl. Phys. 93, 3002 (2003).

${ }^{17}$ J. Neidhardt, L. Hultman, and Zs. Czigány, Carbon 42, 2734 (2004).

${ }^{18}$ S. M. Rossnagel, J. Vac. Sci. Technol. A 7, 1025 (1989).

${ }^{19}$ J. J. Cuomo, J. P. Doyle, J. Bruley, and J. C. Liu, Appl. Phys. Lett. 58, 466 (1991). 